\title{
A cholecystocolonic fistula caused by penetration of a double-pigtail plastic stent after endoscopic transpapillary gallbladder stenting
}

Endoscopic transpapillary gallbladder stenting is currently indicated to treat acute cholecystitis, and a double-pigtail plastic stent is usually placed [1-3]. No case of cholecystocolonic fistula caused by endoscopic transpapillary gallbladder stenting has been reported.

An 87-year-old man was admitted to our hospital for the treatment of right hypochondralgia. Computed tomography revealed gallbladder distension and wall thickening ( $\bullet$ Fig. 1). Magnetic resonance cholangiopancreatography revealed a gallstone in the neck of the gallbladder. Percutaneous transhepatic gallbladder drainage was contraindicated because of anatomical inaccessibility, and endoscopic naso-gallbladder drainage was associated with a risk for tube removal by the patient. Therefore, we performed endoscopic transpapillary gallbladder stenting with a double-pigtail stent (CX-T stent, $7 \mathrm{Fr} \times 12 \mathrm{~cm}$; Gadelius Medical K.K., Tokyo, Japan) ( Fig.2). The acute cholecystitis resolved after endoscopic transpapillary gallbladder stenting, and the patient was discharged without a cholecystectomy or removal of the plastic stent.

After 18 months, the patient was readmitted with recurrent right hypochondralgia. Computed tomography revealed fat stranding around the gallbladder and showed the proximal pigtail to be located in the colonic lumen ( Fig.3).

At emergency surgery, we found the colon adherent to the gallbladder, which was affected by acute cholecystitis; in addition, the proximal pigtail had penetrated the walls of both the gallbladder body

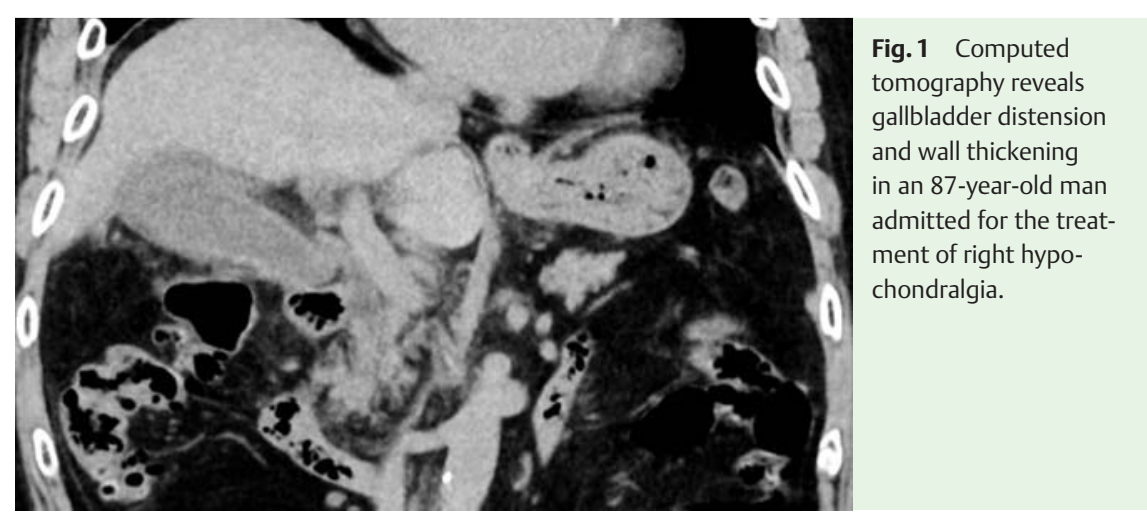

and the transverse colon ( $\bullet$ Fig.4). The patient underwent an emergency cholecystectomy and partial colectomy; the final diagnosis was acute cholecystitis associated with cholecystocolonic fistula, caused by the plastic stent.

Endoscopic transpapillary gallbladder drainage is preferred in patients in whom percutaneous transhepatic gallbladder drainage is contraindicated, such as those who have severe coagulopathy or thrombocytopenia, or in whom the lesion is anatomically inaccessible [3]. Long-term placement of a gallbladder stent is used to prevent the recurrence of acute cholecystitis [1]. It is wise to remember that a cholecystocolonic fistula is one possible adverse event after endoscopic transpapillary gallbladder stenting, even when a double-pigtail plastic stent has been used.

Endoscopy_UCTN_Code_TTT_1AO_2AZ

Competing interests: None

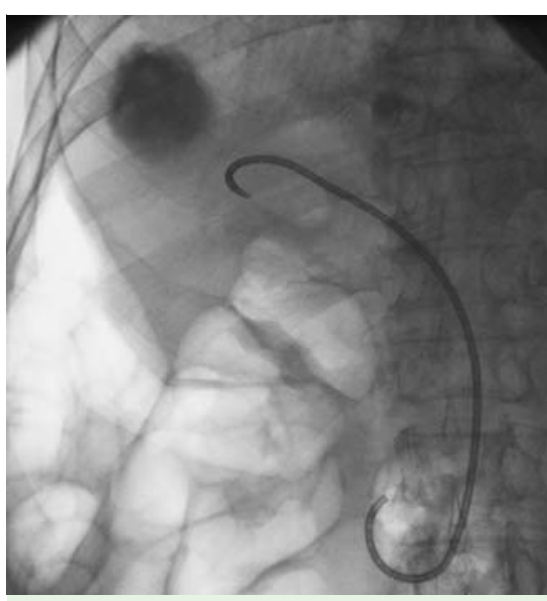

Fig.2 Endoscopic transpapillary gallbladder stenting with a double-pigtail plastic stent. 


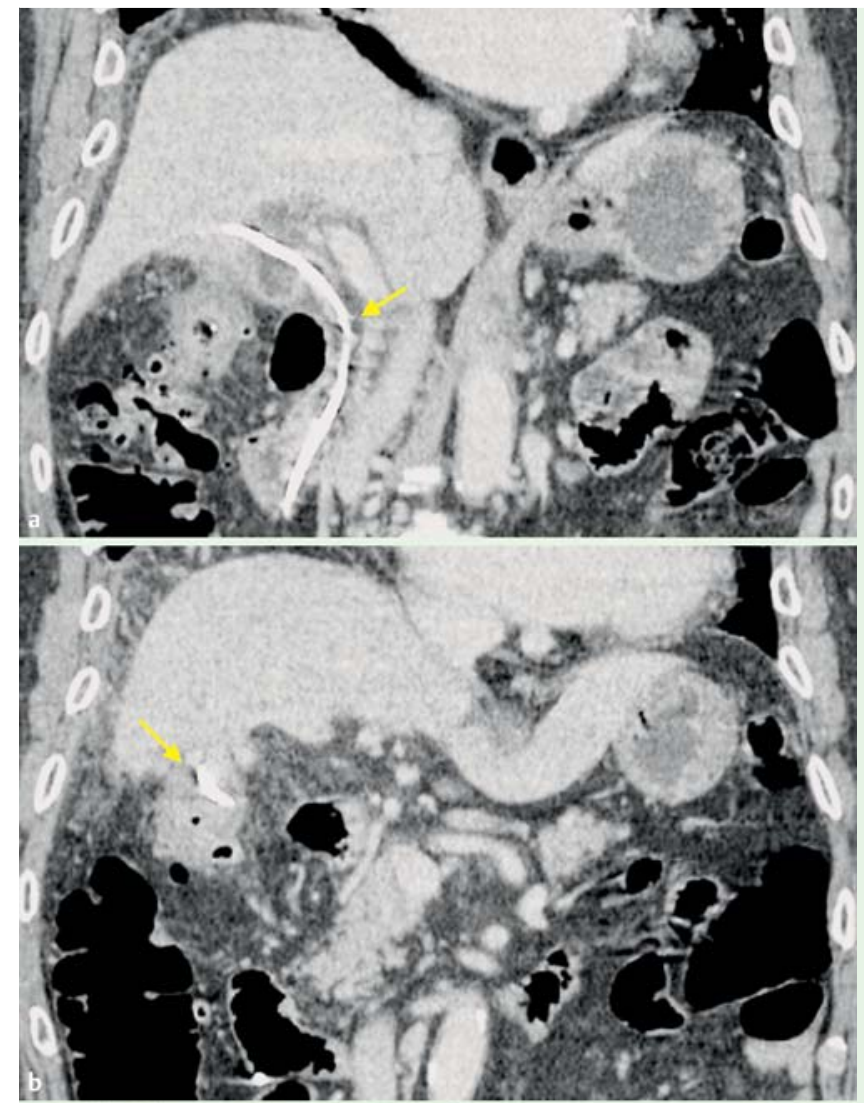
plastic stent. a Endo-
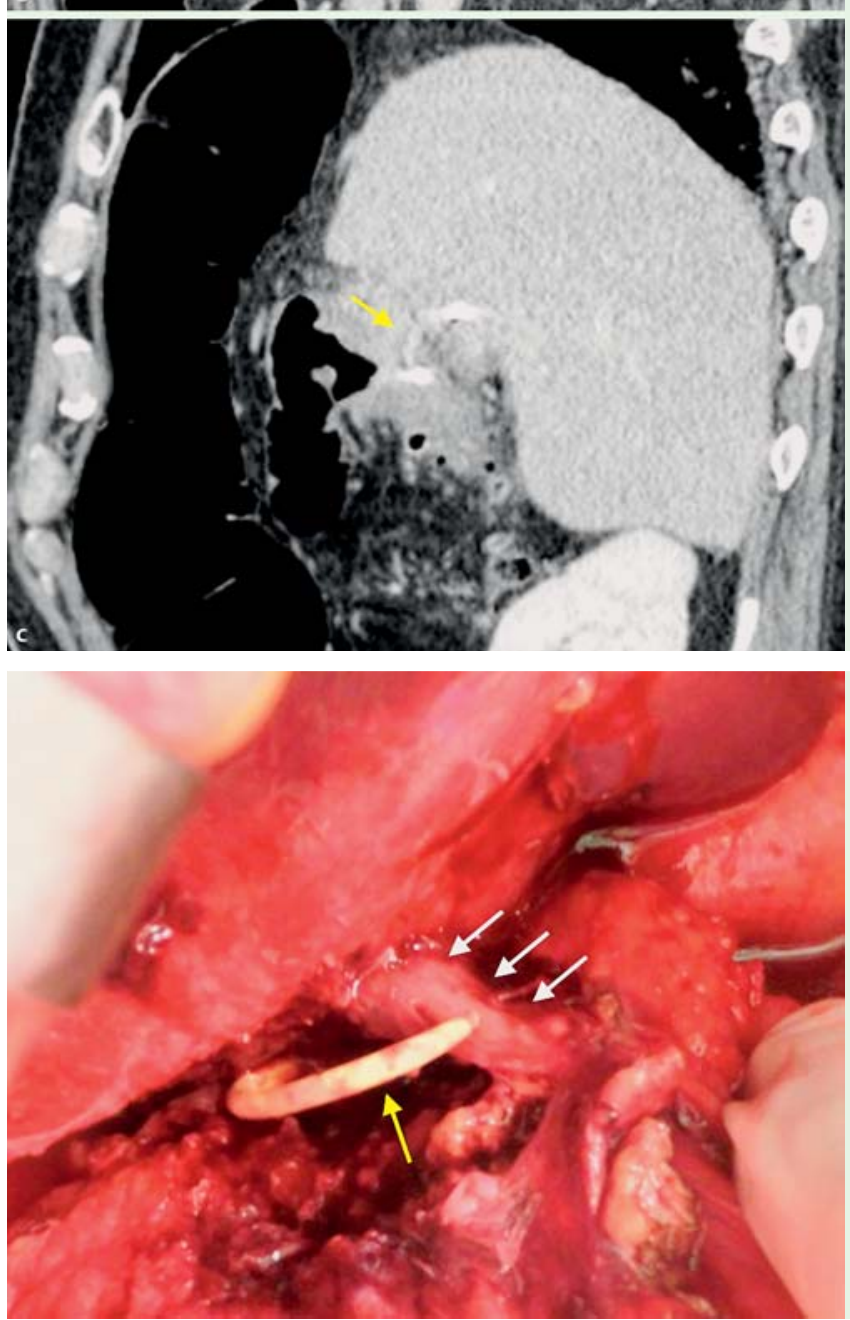

Fig. 3 Computed tomography reveals a cholecystocolonic fistula caused by the scopic transpapillary gallbladder stent (yellow arrow). b Proximal pigtail of the plastic stent located in the colonic lumen (yellow arrow). c Proximal pigtail penetrating the walls of both the gallbladder body and transverse colon (yellow arrow).

Itaru Naitoh', Takahiro Nakazawa', Katsuyuki Miyabe ${ }^{1}$, Koji Mizoguchi², Masahiro Kimura², Hiromitsu Takeyama², Takashi Joh ${ }^{1}$

${ }^{1}$ Department of Gastroenterology and Metabolism, Nagoya City University Graduate School of Medical Sciences, Nagoya, Japan

2 Department of Gastroenterological Surgery, Nagoya City University Graduate School of Medical Sciences, Nagoya, Japan

\section{References}

1 Lee TH, Park DH, Lee SS et al. Outcomes of endoscopic transpapillary gallbladder stenting for symptomatic gallbladder diseases: a multicenter prospective follow-up study. Endoscopy 2011; 43: $702-708$

2 Itoi T, Coelho-Prabhu N, Baron TH. Endoscopic gallbladder drainage for management of acute cholecystitis. Gastrointest Endosc 2010; 71: $1038-1045$

3 Itoi $T$, Sofuni $A$, Itokawa $F$ et al. Endoscopic transpapillary gallbladder drainage in patients with acute cholecystitis in whom percutaneous transhepatic approach is contraindicated or anatomically impossible (with video). Gastrointest Endosc 2008; 68: $455-460$

\section{Bibliography}

Dol http://dx.doi.org/

10.1055/s-0034-1392613

Endoscopy 2015; 47: E399-E400

(c) Georg Thieme Verlag KG

Stuttgart · New York

ISSN 0013-726X

\section{Corresponding author}

\section{Itaru Naitoh, MD, PhD}

Department of Gastroenterology and Metabolism Nagoya City University Graduate School of Medical Sciences

1 Kawasumi

Mizuho-cho

Mizuho-ku

Nagoya 467-8601

Fig. 4 Intraoperative Japan

Fax: +81-52-852-0952

findings show penetration of the proximal pigtail (yellow arrow) from the lumen of the gallbladder through the wall of the gallbladder (white arrows). 